\title{
Molecular and karyological data confirm that the enigmatic genus Platypholis from Bonin-Islands (SE Japan) is phylogenetically nested within Orobanche (Orobanchaceae)
}

\author{
$\mathrm{Xi} \mathrm{Li}^{1} \cdot$ Tae-Soo Jang ${ }^{1} \cdot$ Eva M. Temsch $^{1} \cdot$ Hidetoshi Kato $^{2} \cdot$ Koji Takayama $^{3}$. \\ Gerald M. Schneeweiss ${ }^{1}$
}

Received: 9 February 2016 / Accepted: 26 October 2016 / Published online: 21 December 2016

(c) The Author(s) 2017. This article is published with open access at Springerlink.com

\begin{abstract}
Molecular phylogenetic studies have greatly improved our understanding of phylogenetic relationships of non-photosynthetic parasitic broomrapes (Orobanche and related genera, Orobanchaceae), but a few genera have remained unstudied. One of those is Platypholis, whose sole species, Platypholis boninsimae, is restricted to the Bonin-Islands (Ogasawara Islands) about $1000 \mathrm{~km}$ southeast of Japan. Based on overall morphological similarity, Platypholis has been merged with Orobanche, but this hypothesis has never been tested with molecular data. Employing maximum likelihood and Bayesian analyses on a family-wide data set (two plastid markers, matK and rps2, and three nuclear markers, ITS, phyA and $p h y B$ ) as well as on an ITS data set focusing on Orobanche s. str., it is shown that $P$. boninsimae Maxim. is phylogenetically closely linked to or even nested within Orobanche s. str. This position is supported both by morphological evidence and by the newly obtained chromosome number of $2 n=38$, which is characteristic for the genus Orobanche s. str.
\end{abstract}

Electronic supplementary material The online version of this article (doi:10.1007/s10265-016-0888-y) contains supplementary material, which is available to authorized users.

Gerald M. Schneeweiss

gerald.schneeweiss@univie.ac.at

1 Department of Botany and Biodiversity Research, University of Vienna, Rennweg 14, 1030 Vienna, Austria

2 Makino Herbarium, Tokyo Metropolitan University, 1-1 Minami-Ohsawa, Hachioji-shi, Tokyo 192-0397, Japan

3 Museum of Natural and Environmental History, Shizuoka, 5762 Oya, Suruga-ku, Shizuoka-shi, Shizuoka 422-8017, Japan
Keyword Bonin Islands · Chromosome number · Molecular phylogeny · Orobanche . Parasitic plant . Platypholis

\section{Introduction}

Orobanchaceae have become a model group for studying the evolution of parasitic flowering plants (Westwood et al. 2010), because the family includes the full range of nutritional modes (from nonparasitic via photosynthetic parasitic to non-photosynthetic parasitic) as well as a number of pest species parasitic on economically important crop plants (Heide-Jørgensen 2008). For a better understanding of the evolution of parasitism and associated changes, a sound phylogenetic framework is needed. Despite enormous progress with respect to elucidating phylogenetic relationships within Orobanchaceae (McNeal et al. 2013), a considerable number of genera have not been studied yet using molecular phylogenetic approaches (Schneeweiss 2013), rendering our knowledge on phylogenetic relationships in Orobanchaceae incomplete.

The highest diversity of non-photosynthetic parasitic (i.e., holoparasitic) species within Orobanchaceae is found in the exclusively holoparasitic Orobanche clade. While relationships and circumscription of its constituent genera are largely established (Schneeweiss 2013), molecular data are still lacking for the two East Asian genera Phacellanthus Siebold and Zucc. and Platypholis Maxim., the latter the focus of the present study. Platypholis contains a single species, $P$. boninsimae Maxim. (Fig. 1). It is endemic to the Bonin-Islands (Ogasawara I.) about $1000 \mathrm{~km}$ southeast of Japan, where it grows in shady, moist forests parasitizing mainly Callicarpa subpubescens Hook. and Arn. (Tuyama 1937). Platypholis was first described by Maximowicz 


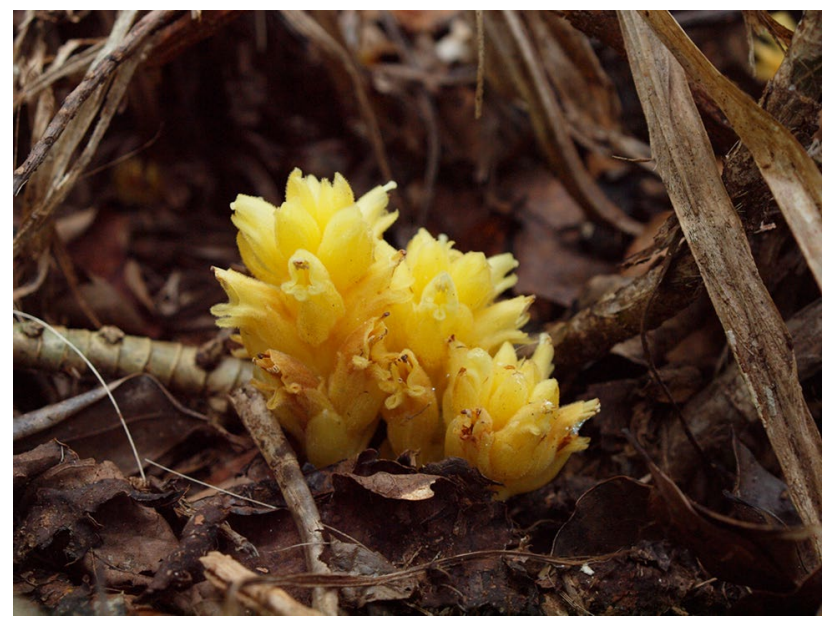

Fig. 1 Habit of Orobanche boninsimae (syn. Platypholis b.) on Mt. Chibusayama, Hahajima Island (photo by H. Kato)

(1886). He contrasted Platypholis with Conopholis Wallr., Boschniakia C.A.Mey. ex Bong., and Lathraea L. (the last not belonging to the Orobanche clade: McNeal et al. 2013; Schneeweiss 2013) that differ from Platypholis by nonexserted stamens as well as calyx and/or ovary structure. In conflict with Maximowicz's (1886) description, BeckManngetta (1890, 1895, 1930) considered Platypholis to have three carpels with six placentas (instead of two carpels with four placentas) and consequently put it, together with Xylanche Beck (now merged with Boschniakia s. str.: Schneeweiss 2013) and Phacellanthus, into his Orobanchaceae tricarpellatae. Tuyama (1937) confirmed the observations of Maximowicz (1886) concerning the ovary structure of Platypholis. Furthermore, he considered Platypholis to be morphologically sufficiently similar to Orobanche s. 1. to actually merge both genera and treat $P$. boninsimae as Orobanche boninsimae (Maxim.) Tuyama (Tuyama 1946). None of these hypotheses has, however, been tested with molecular data yet.

Here we want to clarify the phylogenetic position of Platypholis by testing previous hypotheses with respect to the phylogenetic position of Platypholis as distinct from Orobanche L. (Beck-Mannagetta 1890, 1895, 1930; Maximowicz 1886; Zhang 1988) versus within Orobanche (Tuyama 1937, 1946). To this end, we conducted phylogenetic analyses on a family-wide data set (comprising two plastid markers, $m a t K$ and $r p s 2$, and three nuclear markers, ITS, phyA and $p h y B$ ) as well as on an ITS data set focusing on Orobanche s. str. (see Schneeweiss 2013, for details on this narrower circumscription of Orobanche). As chromosome numbers and genome size data have been found to be phylogenetically informative in the Orobanche clade in general and in Orobanche s. 1. in particular (Schneeweiss et al. 2004b; Weiss-Schneeweiss et al. 2006), these data were obtained as well. Specifically, if Platypholis indeed belongs to Orobanche (Tuyama 1937, 1946) we expect Platypholis to have a chromosome base number of $x=19$.

\section{Materials and methods}

\section{Plant material}

Material of Platypholis was collected in 2014 in Higashidaira, Chichijima Island, Ogasawara (Bonin) Islands, Japan; the voucher is deposited at WU. For karyological and cytological investigation, young flower buds were fixed in the field in 3:1 ethanol:glacial acetic acid for at least $24 \mathrm{~h}$ at room temperature and stored at $-20^{\circ} \mathrm{C}$ until further use.

\section{DNA extraction, PCR and sequencing}

Total DNA was extracted using the DNeasy Plant Mini Kit (Qiagen, Hilden, Germany) following the manufacturer's instructions. Two plastid loci ( $m a t K, r p s 2)$ as well as three nuclear loci (ITS, phyA and $p h y B$ ) that have been successfully used in previous phylogenetic studies of Orobanchaceae (McNeal et al. 2013) were amplified using primers listed in Table 1; new or modified primers were designed by eye from available alignments. Amplification of the plastid markers and of ITS was done in a volume of $15.7 \mu \mathrm{L}$ containing $7 \mu \mathrm{L}$ KAPA2G Fast2x ReadyMix (Peqlab, Vienna, Austria), $0.5 \mu \mathrm{L}$ each of $10 \mu \mathrm{M}$ primer, $1 \mu \mathrm{L}$ of DNA extract of unknown concentration, and $7 \mu \mathrm{L}$ sterile water. Amplification of the two phytochrome regions was done in a volume of $15.5 \mu \mathrm{L}$ containing $0.375 \mathrm{U}$ of Platinum High Fidelity Taq (Invitrogen, Carlsbad, California), $1.5 \mu \mathrm{L}$ of $10 \times$ PCR buffer, $0.8 \mu \mathrm{L}$ of $50 \mathrm{mM} \mathrm{MgSO}, 0.15 \mu \mathrm{L}$ of $10 \mathrm{mM}$ dNTPs, $0.5 \mu \mathrm{L}$ each of $10 \mu \mathrm{M}$ primer, $0.7 \mu \mathrm{L}$ of DNA extract of unknown concentration and $10.85 \mu \mathrm{L}$ sterile water. PCR conditions for ITS amplification were: denaturation for $4 \mathrm{~min}$ at $94^{\circ} \mathrm{C} ; 35$ cycles each with $30 \mathrm{~s}$ at $94^{\circ} \mathrm{C}, 30 \mathrm{~s}$ at $48^{\circ} \mathrm{C}, 1 \mathrm{~min}$ at $72^{\circ} \mathrm{C}$; and final elongation for $10 \mathrm{~min}$ at $72^{\circ} \mathrm{C}$. For the remaining four loci (rps2, matK, $p h y A$ and $p h y B)$ a touchdown PCR protocol was used, thus obviating potential problems due to degenerate primers. The PCR conditions were: $2 \mathrm{~min}$ at $94^{\circ} \mathrm{C} ; 9$ cycles each with $30 \mathrm{~s}$ at $94^{\circ} \mathrm{C}, 15 \mathrm{~s}$ at $67^{\circ} \mathrm{C}$ (decreasing the annealing temperature by $1{ }^{\circ} \mathrm{C}$ at each subsequent cycle, so that in the 9 th cycle the annealing temperature was $59^{\circ} \mathrm{C}$ ), $90 \mathrm{~s}$ at $70{ }^{\circ} \mathrm{C} ; 21$ cycles each with $30 \mathrm{~s}$ at $94^{\circ} \mathrm{C}, 30 \mathrm{~s}$ at $57^{\circ} \mathrm{C}, 90 \mathrm{~s}$ at $70^{\circ} \mathrm{C} ; 12$ cycles with $30 \mathrm{~s}$ at $94^{\circ} \mathrm{C}, 45 \mathrm{~s}$ at $62^{\circ} \mathrm{C}, 90 \mathrm{~s}$ at $70^{\circ} \mathrm{C}$; a final elongation for $7 \mathrm{~min}$ at $70^{\circ} \mathrm{C}$. PCR products were purified using Exonuclease I and FastAP thermosensitive alkaline phosphatase (Fisher Scientific, St. Leon-Rot, Germany) following the manufacturer's instructions. Cycle sequencing reactions were performed using $5 \mu \mathrm{L}$ of purified 
Table 1 Amplification primers

\begin{tabular}{|c|c|c|}
\hline \multicolumn{2}{|l|}{ Primer } & \multirow[t]{2}{*}{ References } \\
\hline Name & Sequence $\left(5^{\prime}-3^{\prime}\right)$ & \\
\hline \multicolumn{3}{|l|}{ matK } \\
\hline $\operatorname{trnK} 3914 \mathrm{~F}$ di & GGGGTTGCTAACTCAACGG & Johnson and Soltis (1995) \\
\hline matK550Fca & TGGAAATCTTGGTTCAAACTCTTCG & This study \\
\hline matK-50Fdi & GTTTTGACTGTATCGCACTATGTATC & Demaio et al. (2011) \\
\hline matK 950r & CCACARCGAAAAATRMCATTGCC & Young et al. (1999) \\
\hline matK 1349r & CTTTTGTGTTTCCGAGCYAAAGTTC & Young et al. (1999) \\
\hline $\operatorname{trnK}-\mathrm{R} 2 *$ & CTCGAACCCGGAACTAGTCGG & Castello et al. (2016) \\
\hline \multicolumn{3}{|l|}{ rps 2} \\
\hline rps2-47F & CTCGTTTTTTATCTGAAGCCTG & dePamphilis et al. (1997) \\
\hline rps $2-58 \mathrm{~F}$ & AAATGGAATCCTAAAATGGCA & This study \\
\hline rps2-661R & ACCCTCACAAATAGCGAATACCAA & dePamphilis et al. (1997) \\
\hline \multicolumn{3}{|l|}{ ITS } \\
\hline ITS AB101 & ACGAATTCATGGTCCCGTGAAGTGTTCG & Schneeweiss et al. (2004a) \\
\hline ITS AB102 & TAGAATTCCCCGGTTCGCTCGCCGTTAC & Schneeweiss et al. (2004a) \\
\hline \multicolumn{3}{|l|}{ phyA } \\
\hline PHYA230f & GACTTTGARCCNGTBAAGCCTTAYG & Mathews and Donoghue (1999) \\
\hline PHYA_Newa678r & GTCTCRATCARACGAACCATCTC & This study \\
\hline \multicolumn{3}{|l|}{ phyB } \\
\hline PHYB7f & CACAGGATAGAYGTRGGRGT & This study \\
\hline NewPHYB_b678r.oro & GTCTCТАТСААССТААYСАТСТС & This study (modified from McNeal et al. 2013) \\
\hline
\end{tabular}

template, $1 \mu \mathrm{L}$ of primer $(3.2 \mu \mathrm{M})$ and $1 \mu \mathrm{L}$ BigDye Terminator (Applied Biosystems, Foster City, California), cleaned with Sephadex G-50 Fine (GE Healthcare Bio-Sciences, Uppsala, Sweden) and sequenced on an ABI 3730 DNA Analyzer capillary sequencer (Applied Biosystems).

\section{Phylogenetic analyses}

Sequences were assembled and edited using SeqMan II 5.05 (DNAStar Inc., Madison, USA). The newly obtained data of Platypholis were added and aligned by eye to the existing single and combined marker alignments of McNeal et al. (2013), available from TreeBase (http://treebase. org) under study number 13942, using BioEdit 7.2.1 (Hall 1999). Likewise, ITS sequences of Platypholis were added to the alignment of Frajman et al. (2013) that focuses on Orobanche s. str. and consequently has a much denser sampling within that genus. Sequence alignments are available from ResearchGate under doi:10.13140/RG.2.1.4124.1203.

The best-fit substitution models were identified using the Akaike Information Criterion (AIC) and the Bayesian Information Criterion (BIC) as implemented in jModelTest 2.1.6 (Darriba et al. 2012). We tested 44 substitution models (11 substitution schemes, allowing unequal frequencies and/or rate heterogeneity across sites modeled by a gamma distribution, but no proportion of invariable sites due to identifiability issues: Yang 2014) on maximum-likelihood (ML) optimized topologies obtained following SPR (Subtree Pruning and Regrafting) branch swapping. For each dataset, the General Time Reversible (GTR) model (Tavaré 1986) including rate heterogeneity across sites described by a gamma distribution was selected. Maximum likelihood analyses were conducted using RAxML 8.1 (Stamatakis et al. 2014) employing the fast bootstrap approach (Stamatakis et al. 2008) with 1000 bootstrap replicates. Bayesian inference was done using MrBayes 3.2.3 (Ronquist et al. 2012). Values for all parameters, such as the shape of the gamma distribution (approximated using six discrete rate categories) or the substitution rates, were estimated during the analysis. For partitioned analyses (combined data set only), partitions were allowed to evolve under different rates (ratepr $=$ variable). Four Monte Carlo Markov (MCMC) chains were run simultaneously starting from different random starting trees for 20 million generations, with trees sampled every 5000th generation. After combining 3600 trees from each run (i.e., after discarding $10 \%$ of samples as burn-in, when the MCMC chain had reached stationarity as confirmed by visual inspection of traces and standard deviations of split variances being below 0.01), posterior probabilities were estimated from these 14,400 posterior trees and were plotted on a majority rule consensus tree. 


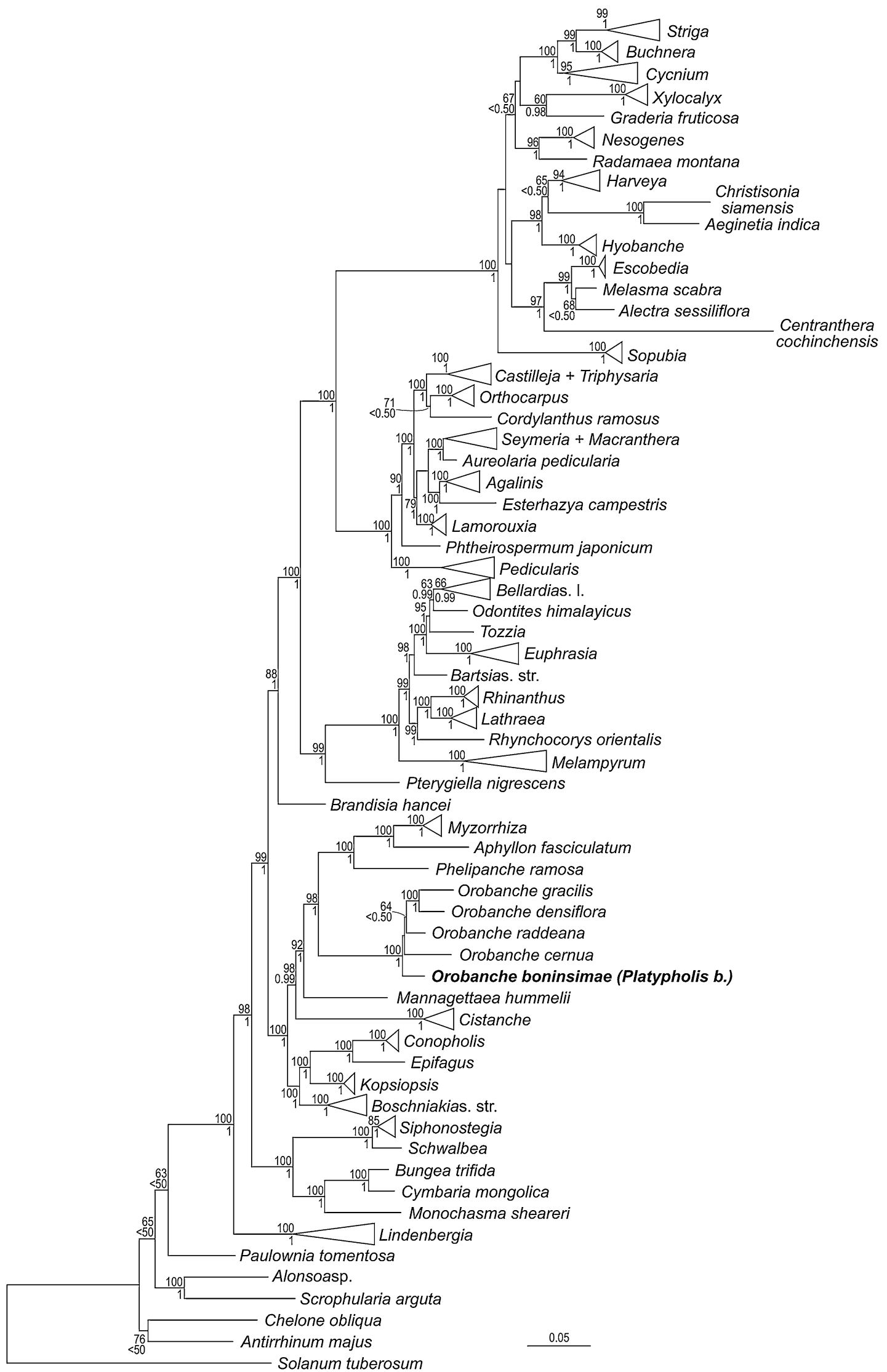


4Fig. 2 Phylogenetic placement of Orobanche boninsimae (syn. Platypholis $b$.) within Orobanchaceae inferred using maximum likelihood on a five marker combined data set (matK, rps2, ITS, phyA, $p h y B)$. Numbers at branches are maximum likelihood bootstrap support values (60 or higher) and posterior probabilities ( 0.5 or higher). Solanum tuberosum $\mathrm{L}$. was chosen as outgroup

\section{Chromosome number and genome size}

The chromosome number of Platypholis was determined from meiotic divisions in pollen mother cells (PMCs) and from first mitosis in developing microspores using the standard Feulgen staining technique (Schneeweiss et al. $2004 b$ ). Fixed material was hydrolyzed in $5 \mathrm{~N} \mathrm{HCl}$ for $30 \mathrm{~min}$ at room temperature, washed with tap water and stained with Schiff's reagent (Merck, Darmstadt, Germany) in darkness for $1 \mathrm{~h}$ (Jang et al. 2013). Chromosome spreads were prepared by squashing stained anthers in a drop of acetic acid (60\%) under the cover-slip, and analyzed using an AxioImager M2 microscope (Carl Zeiss, Vienna, Austria). Preparations with a minimum of 15 good quality chromosome spreads were analyzed. Images were acquired with a CCD camera and files processed using AxioVision 4.8 (Carl Zeiss). The karyotype was made from these images in PhotoPaint X7 (Corel Corp., Ottawa, Ontario).

Fixed flower buds were transferred to ethanol and stored in the deep freezer. For preparation for genome size estimation, plant tissue was rehydrated and hydrolyzed for $60 \mathrm{~min}$ in $5 \mathrm{~N} \mathrm{HCl}$ at $20^{\circ} \mathrm{C}$ (Greilhuber and Temsch 2001) together with root tips from the internal standard (Pisum sativum $\mathrm{L}$. 'Kleine Rheinländerin', $1 \mathrm{C}=4.42$ pg: Greilhuber and Ebert 1994). After washing with water, the samples were stained with Schiff's reagent over-night in the refrigerator. The dye was removed by washing six times with $\mathrm{SO}_{2}$-water over a total period of $45 \mathrm{~min}$. Subsequently, the stained tissue was squashed on slides, frozen, and after removal of cover slips fixed in 96\% ethanol, dried and stored until measurement. Measurements of the Integrated Optical Densities (IOD) were conducted on the Cell Image Retrieval and Evaluation System (CIRES, Kontron, Munich), which was equipped with a CCD DXC 390P camera (Sony, Tokyo, Japan) and an Axioscope microscope (Carl Zeiss). From each slide, for both the object and the internal standard, 10 prophase and 10 telophase nuclei were measured. Per slide a $1 \mathrm{C}$-value was calculated using the formula (mean $\mathrm{IOD}_{\mathrm{Obj}} /$ mean $\left.\mathrm{IOD}_{\mathrm{Std}}\right) * 1 \mathrm{C}$-value $\mathrm{Std}_{\mathrm{S}}$.

\section{Results}

Newly obtained sequences of $m a t K, r p s 2$, ITS, phyA and phy $B$ are available from GenBank under accession numbers KU647699, KU647702, KU647698, KU647700 and
KU647701, respectively. Phylogenetic analyses of the family-wide data sets (single marker and concatenated data sets) congruently place Platypholis within the Orobanche clade as sister to or nested within Orobanche s. str. (BS = 100, PP =1; Online Resource 1; Fig. 2), but low resolution and/or insufficient support (except for ITS: Fig. 3; Fig. S3 in Online Resource 1) prevent the precise phylogenetic position of Platypholis being identified (Fig. 2; Online Resource 1). Although phylogenetic relationships among lineages inferred from single markers are not fully congruent (Online Resource 1), well-supported incongruences involving Platypholis are lacking and those involving the remaining taxa have been found to be not statistically significant (McNeal et al. 2013). Analyses of a data set focusing on Orobanche s. str. place Platypholis firmly within Orobanche s. str. $(\mathrm{BS}=87, \mathrm{PP}=1.00$, Fig. 3$)$, where it is inferred as sister species to $O$. coerulescens Stephan ( $\mathrm{BS}=74, \mathrm{PP}=0.97$, Fig. 3).

Platypholis is diploid with a chromosome number of $2 n=2 x=38$ (Fig. 4). All chromosomes are metacentric to submetacentric and their lengths range from 2 to $5 \mu \mathrm{M}$ (Fig. 4), resulting in a Haploid Karyotype Length (HKL) of $54.83 \mu \mathrm{M}$. The nuclear DNA amount (1C) of Platypholis, calculated as average from four slide pairs, is $7.28 \mathrm{pg}$ (S.D. 0.1805 , C.V. $2.48 \%$ ).

\section{Discussion}

The monotypic genus Platypholis has not been included in any molecular phylogenetic study of Orobanchaceae to date and its precise placement within the family remained uncertain (Schneeweiss 2013). Using data from two plastid and three nuclear loci, it is shown that Platypholis phylogenetically belongs to the Orobanche clade (Fig. 2, Online Resource 1) and is sister to or even nested within Orobanche s. str. (Fig. 3). The uncertainty concerning the precise placement of Platypholis may be due to issues of paralogy in nuclear markers, especially ITS (Álvarez and Wendel 2003). As neither gel visualization of PCR products nor direct sequencing indicated any presence of paralogues and as there are no strongly supported, but rather contradicting phylogenetic relationships inferred from plastid versus nuclear markers (Online Resource 1), we consider it unlikely that our inferences are misled by paralogues. Alternatively, incongruences between different markers might be due to incomplete lineage sorting, which can be accommodated by using species tree estimation methods. This will, however, require much larger data sets, especially if a possible negative affect of missing data is to be avoided (Xi et al. 2016), which goes beyond the scope of this study. 


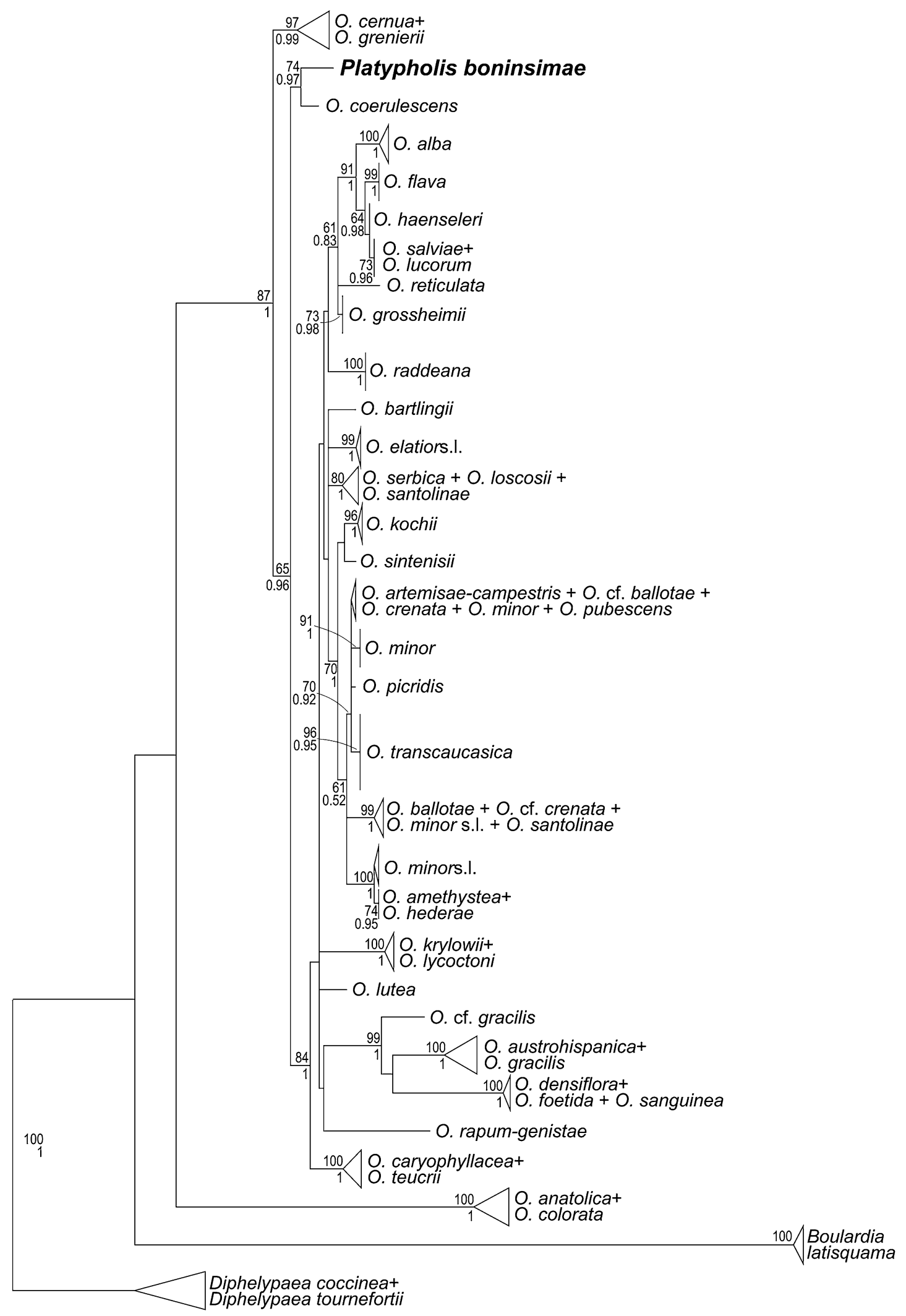

Fig. 3 Phylogenetic placement of Orobanche boninsimae (syn. Platypholis b.) within Orobanche s. str. (i.e., also excluding Boulardia: Schneeweiss 2013) inferred using maximum likelihood on an ITS data set. Numbers at branches are maximum likelihood boot- strap support values (60 or higher) and posterior probabilities $(0.5$ or higher). Diphelypaea Nicolson was chosen as outgroup (Schneeweiss et al. 2004a) 


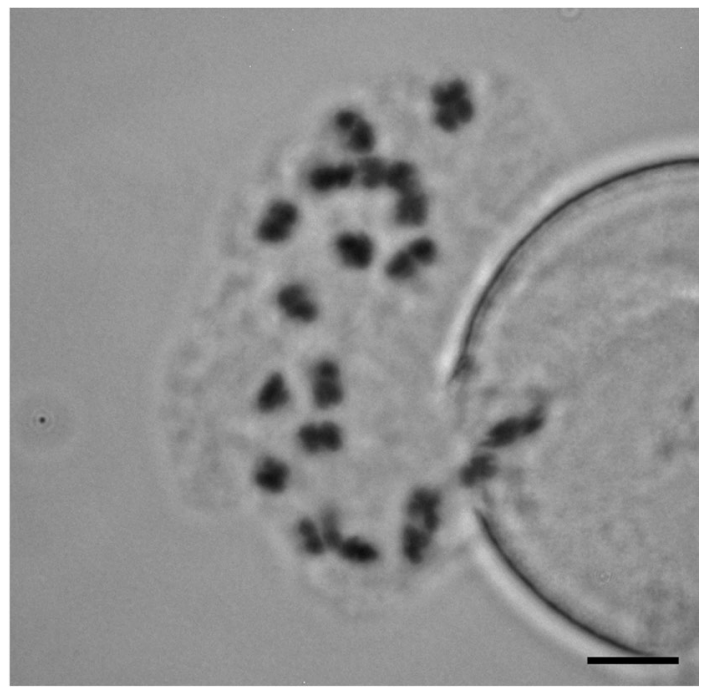

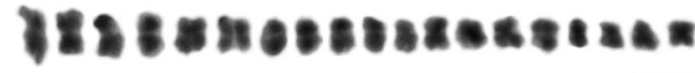

Fig. 4 Chromosomes and karyotype of Orobanche boninsimae (syn. Platypholis b.): $n=19$ (metaphase of first mitotic division in microspore). Scale bar $5 \mu \mathrm{m}$

A close relationship of Platypholis and Orobanche s. str. is also supported by the shared chromosome number of $2 n=38$ (Fig. 4; Schneeweiss et al. 2004b). Hence, both molecular phylogenetic and karyological data refute (implicit) hypotheses of Maximowicz (1886) and BeckMannagetta $(1890,1895,1930)$ on a closer relationship to Lathraea, Conopholis, and/or Boschniakia (no data available for Phacellanthus) and instead support Tuyama (1937, 1946), who suggested a close relationship to Orobanche. Tuyama (1937) also noted several morphological characters that Platypholis shares with all or at least some species of Orobanche s. str., including the absence of bracteoles, the flowers being sessile, the calyx being divided into two lateral sepals, the basal insertion of stamens, and the ovary structure (two-carpellate ovaries with four placentae). The last is of particular relevance, because BeckMannagetta $(1890,1895,1930)$ placed Platypholis in his Orobanchaceae tricarpellatae based on the perceived presence of three carpels and six separate placentae (see Fig. 24G in Beck-Mannagetta 1930: 331), while he classified Orobanche s. str. (as $O$. sect. Ospreolon) within his Orobanchaceae bicarpellatae, due to the presence of two carpels and four separate placentae. Beck's observations are even more puzzling, because Maximowicz (1886), when describing Platypholis, had already indicated the presence of four placentae only, which Beck dutifully reported, albeit with reservations (Beck-Mannagetta 1930: 332 "sec. Maximowicz solum 4": "according to Maximowicz only 4"). Taxonomically, the genus Platypholis can no longer be upheld and, following Tuyama (1937, 1946) and subsequent Japanese authors, its single species is to be treated as member of Orobanche s. str. as $O$. boninsimae.

The phylogenetic placement of $O$. boninsimae within Orobanche s. str. is less certain. A closer relationship to O. coerulescens, as suggested by ITS data (Fig. 3), is supported by geographic proximity, as $O$. coerulescens (lacking from the Bonin Islands) is the sole Orobanche species occurring on the main islands of Japan (Shimane). Orobanche boninsimae differs from $O$. coerulescens and other Orobanche species by having exserted stamens (unique within the genus; Fig. 1), a stem that is strongly branched at the caudex, larger chromosomes $(2-5 \mu \mathrm{M}$ vs. 1-3 $\mu \mathrm{M}$ : Schneeweiss et al. 2004b) and a correspondingly larger genome $(7.28 \mathrm{pg} / 1 \mathrm{C}$ vs. $1.45-5.83 \mathrm{pg} / 1 \mathrm{C}$ : WeissSchneeweiss et al. 2006). The considerably larger genome observed in $O$. boninsimae may be connected to life-history (the species is perennial: Tuyama 1937; reports by Abe (2006) that $O$. boninsimae is annual are incorrect) or changes in breeding system, as noted in other plant groups (Albach and Greilhuber 2004; Price et al. 2005).

Acknowledgements Open access funding provided by University of Vienna. We thank Sarah Mathews (Australian National University) for help with amplification protocols for phytochrome genes. Financial support from the program of China Scholarships Council (No. 201206100007) to X. L. is gratefully acknowledged.

Open Access This article is distributed under the terms of the Creative Commons Attribution 4.0 International License (http:// creativecommons.org/licenses/by/4.0/), which permits unrestricted use, distribution, and reproduction in any medium, provided you give appropriate credit to the original author(s) and the source, provide a link to the Creative Commons license, and indicate if changes were made.

\section{References}

Abe $\mathrm{T}$ (2006) Threatened pollination systems in native flora of the Ogasawara (Bonin) Islands. Ann Bot 98:317-334. doi:10.1093/ $\mathrm{aob} / \mathrm{mcl117}$

Albach DC, Greilhuber J (2004) Genome size variation and evolution in Veronica. Ann Bot 94:897-911. doi:10.1093/aob/mch219

Álvarez I, Wendel JF (2003) Ribosomal ITS sequences and plant phylogenetic inference. Mol Phylogen Evol 29:417-434. doi:10.1016/S1055-7903(03)00208-2

Beck-Mannagetta G (1890) Monographie der Gattung Orobanche. Theodor Fischer, Cassel

Beck-Mannagetta G (1895) Orobanchaceae. In: Engler A, Prantl K (eds) Die natürlichen Pflanzenfamilien IV 3b. Wilhelm Engelmann, Leipzig, pp 123-132. doi:10.5962/bhl.title.4635

Beck-Mannagetta G (1930) Orobanchaceae. In: Engler A (ed) Das Pflanzenreich IV 261. Wilhelm Engelmann, Leipzig, pp 1-348

Castello LV, Barfuss MHJ, Till W, Galetto L, Chiapella JO (2016) Disentangling the Tillandsia capillaris complex: phylogenetic relationships and taxon boundaries in Andean populations. Bot $\mathbf{J}$ Linn Soc 181(3):391-414. doi:10.1111/boj.12400 
Darriba D, Taboada GL, Doallo R, Posada D (2012) jModelTest 2: more models, new heuristics and parallel computing. Nat Meth 9:772-772. doi:10.1038/nmeth.2109

Demaio PH, Barfuss MHJ, Kiesling R, Till W, Chiapella JO (2011) Molecular phylogeny of Gymnocalycium (Cactaceae): assessment of alternative infrageneric systems, a new subgenus, and trends in the evolution of the genus. Am J Bot 98:1841-1854. doi:10.3732/ajb.1100054

dePamphilis CW, Young ND, Wolfe AD (1997) Evolution of plastid gene rps 2 in a lineage of hemiparasitic and holoparasitic plants: many losses of photosynthesis and complex patterns of rate variation. Proc Natl Acad Sci USA 94:7367-7372

Frajman B, Carlón L, Kosachev P, Sánchez Pedraja O, Schneeweiss GM, Schönswetter P (2013) Phylogenetic position and taxonomy of the enigmatic Orobanche krylowii (Orobanchaceae), a predominatly Asian species newly found in Albania (SE Europe). Phytotaxa 137(1):1-14. doi:10.11646/phytotaxa.137.1.1

Greilhuber J, Ebert I (1994) Genome size variation in Pisum sativum. Genome 37:646-655

Greilhuber J, Temsch EM (2001) Feulgen densitometry: some observations relevant to best practice in quantitative nuclear DNA content determination. Acta Bot Croat 60:285-298

Hall TA (1999) Bioedit: a user-friendly biological sequence alignment editor and analysis program for Windows 95/98/NT. Nucl Acids Symp Ser 41:95-98

Heide-Jørgensen HS (2008) Parasitic flowering plants. Brill, Leiden

Jang TS, Emadzade K, Parker J, Temsch EM, Leitch AR, Speta F, Weiss-Schneeweiss H (2013) Chromosomal diversification and karyotype evolution of diploids in the cytologically diverse genus Prospero (Hyacinthaceae). BMC Evol Biol 13(1):136. doi:10.1186/1471-2148-13-136

Johnson LA, Soltis DE (1995) Phylogenetic inference in Saxifragaceae sensu stricto and Gilia (Polemoniaceae) using matK sequences. Ann Missouri Bot Gard 82:149-175. doi: $10.2307 / 2399875$

Mathews S, Donoghue MJ (1999) The root of angiosperm phylogeny inferred from duplicate phytochrome genes. Science 286:947950. doi:10.1126/science.286.5441.947

Maximowicz CJ (1886) Diagnoses plantarum novarum asiaticarum. VI.-Insunt stirpes quaedam nuper in Japonia detectae. Bull Acad Imp Sci St 31:12-121

McNeal JR, Bennett JR, Wolfe AD, Mathews S (2013) Phylogeny and origins of holoparasitism in Orobanchaceae. Am J Bot 100:971983. doi:10.3732/ajb. 1200448

Price HJ, Dillon SL, Hodnett G, Rooney WL, Ross L, Johnston JS (2005) Genome evolution in the genus Sorghum (Poaceae). Ann Bot 95:219-227. doi:10.1093/aob/mci015

Ronquist F, Teslenko M, van der Mark P, Ayres DL, Darling A, Höhna S, Larget B, Liu L, Suchard MA, Huelsenbeck JP (2012)
MrBayes 3.2: Efficient Bayesian phylogenetic inference and model choice across a large model space. Syst Biol 61:539-542. doi:10.1093/sysbio/sys029

Schneeweiss G (2013) Phylogenetic relationships and evolutionary trends in Orobanchaceae. In: Joel DM, Gressel J, Mussleman LJ (eds) Parasitic Orobanchaceae. Springer, Berlin Heidelberg, pp 243-265

Schneeweiss GM, Colwell AE, Park JM, Jang CG, Stuessy TF (2004a) Phylogeny of holoparasitic Orobanche (Orobanchaceae) inferred from nuclear ITS sequences. Mol Phylogen Evol 30:465-478. doi:10.1016/S1055-7903(03)00210-0

Schneeweiss GM, Palomeque T, Colwell AE, Weiss-Schneeweiss H (2004b) Chromosome numbers and karyotype evolution of holoparasitic Orobanche (Orobanchaceae) and related genera. Am J Bot 91:439-448. doi:10.3732/ajb.91.3.439

Stamatakis A (2014) RAxML version 8: a tool for phylogenetic analysis and post-analysis of large phylogenies. Bioinformatics 30:1312-1313. doi:10.1093/bioinformatics/btu033

Stamatakis A, Hoover P, Rougemont J (2008) A rapid bootstrap algorithm for the RAxML web servers. Syst Biol 57:758-771. doi:10.1080/10635150802429642

Tavaré S (1986) Some probabilistic and statistical problems in the analysis of DNA sequences. In: Miura RM (ed) Some mathematical questions in biology_-DNA sequence analysis (Lectures on Mathematics in the Life Sciences 17). American Mathematical Society, Providence, pp 57-86

Tuyama T (1937) On Platypholis boninsimae Maximowicz and its systematic position. Bot Mag 51:279-285

Tuyama T (1946) Ogasawara-to Tokusan Shimautsubo nitsuite [Orobanche boninsimae endemic to the Ogasawara Islands]. Shigen Kagaku Kenkyusho Iho 10:17-18 (In Japanese)

Weiss-Schneeweiss H, Greilhuber J, Schneeweiss GM (2006) Genome size evolution in holoparasitic Orobanche (Orobanchaceae) and related genera. Am J Bot 93:148-156. doi:10.3732/ajb.93.1.148

Westwood JH, Yoder JI, Timko MP, dePamphilis CW (2010) The evolution of parasitism in plants. Trends Pl Sci 15:227-235. doi:10.1016/j.tplants.2010.01.004

Xi Z, Liu L, Davis CC (2016) The impact of missing data on species tree estimation. Mol Biol Evol 33:838-860. doi:10.1093/molbev/ msv266

Yang Z (2014) Molecular evolution. A statistical approach. Oxford Univ Press, Oxford

Young ND, Steiner KE, dePamphilis CW (1999) The evolution of parasitism in Scrophulariaceae/Orobanchaceae: Plastid gene sequences refute an evolutionary transition series. Ann Miss Bot Garden 86:876-893

Zhang ZY (1988) Taxonomy of the Chinese Orobanche and its relationships with related genera. Acta Phytotaxon Sin 26:394-403 (In Chinese) 